\title{
Association of ectoparasites and gastrointestinal endoparasites and body condition in sheep from four farms of the municipality of Valledupar, Cesar
}

\begin{abstract}
The current study was carried out to evaluate the association between the presence of gastrointestinal ectoparasites and endoparasites with the body condition in sheep sampled in 4 farms located in the municipality of Valledupar, Cesar. The type of study is descriptive, prospective and cross-sectional. Samples were taken from 111 sheep without exclusion of sex distributed in 4 farms in the municipality of Valledupar. The McMaster technique was used to determine the parasite loads of the sheep, later stool cultures were made to the samples that presented high parasite loads, the Baerman technique was applied in order to identify the parasites present in the samples and it was evaluated if there is a relationship between body condition/anemic state, body condition / parasite load and anemic state parasite load using the $\mathrm{R}$ statistical software and the Chi-square test as hypothesis test. The results show that the prevalence in this research was $84.6 \%$ of which $22.5 \%$ of the parasitized sheep had high loads, presenting a higher prevalence of the gastrointestinal endoparasite Haemonchus sp with a percentage of $9.9 \%(11 / 25)$, followed by Cooperia with $6.3 \%(7 / 25)$, Ostertagia sp 2.7\% (3/25), Trichuris sp $0.9 \%(1 / 25)$ Strongyloides $\mathrm{sp}$ $0.9 \%(1 / 25)$, Eimeria $0.9 \%(1 / 25)$ and finally Trichostrongylus with a percentage $0.9 \%$ $(1 / 25)$ for a total of $22.5 \%$ and biparasitism did not occur. No ectoparasites were found in sheep. The association between the body anemic status of the sheep determined by the Famacha technique and the presence of gastrointestinal parasites was $p<0.05$; while the relationship between the body condition in sheep and the parasites presented in them was $\mathrm{p}>0.05$. In conclusion, it is established that if there is an association between Famacha and the presence of gastrointestinal endoparasites, the association between body condition and ovine parasites is not established, taking into account that Famacha turned out to be a useful technique to determine in which anemic state and which the body condition is not associated with the parasite load and is responsible for the fact that this technique is subjective and that therefore the decrease in the body mass and weight of the sheep may be due to various factors and not necessarily to the presence of gastrointestinal endoparasites and ectoparasites, considering that the latter were absent in this research.
\end{abstract}

Volume 9 Issue 3 - 202

\author{
Cañate González Abid Silvestre, ${ }^{1,3}$ Herrera \\ Demares Patricia, ${ }^{2,3}$ Bernal Díaz Ana Karina, ${ }^{4}$ \\ Bolaño Narváez Yessika Paola ${ }^{4}$ \\ 'Zootecnista, Esp. Animal Health, Master Sustainable \\ Development and Environment, Colombia \\ ${ }^{2}$ Bacteriologist, Master in Environmental Sciences, Colombia \\ ${ }^{3}$ Research professor in the Microbiology career, Universidad \\ Popular del Cesar, Colombia \\ ${ }^{4}$ Microbiologist, Universidad Popular del Cesar, Colombia
}

Correspondence: Bolaño Narváez Yessika Paola, Microbiologist, Universidad Popular del Cesar, Colombia, Email Yessika.narvaez@gmail.com

Received: April 14,2021 | Published: May 17, 2021

Keywords: sheep, enteroparasites, ectoparasites, Famacha, McMaster

\section{Abbreviations: $\mathrm{CC}$, body condition}

\section{Introduction}

The greatest challenge that humanity must face in the coming decades is the rational use of natural resources, and at the same time producing a sufficient volume of quality food to satisfy the demands of a growing human population, ${ }^{1}$ which is why it is necessary develop efficient production systems that take advantage of available animal resources and that have an acceptable and sustainable technological level, which combines the productivity of intensive systems with the benefits of extensive ones. ${ }^{2}$ Meat and milk sheep farming is a generalized activity developed practically throughout Colombia, considered as a socio-economic line of great importance for the development of the field ${ }^{2}$ However, the department of Cesar has been facing a series of difficulties related to the productive performance of the animals, ${ }^{3}$ since ovine parasitosis represent one of the most frequent problems that affect the productivity of ruminants causing great losses, especially in tropical regions., this situation represents a limitation and an opportunity to improve sheep production levels in the country.
Based on the above, in the department of Cesar it is necessary to develop efficient parasitic control strategies that allow a greater knowledge of the production and sanitary management of this species, being necessary to know the burden of parasitic infections, species and prevalence, with the help of diagnostic tools such as McMaster and Baermaan that can perhaps be associated with assessment of body state and FAMACHA for the design of control strategies, thus avoiding treatments that can generate resistance, which is what is sought in this work, since These measures have been used by some researchers to contribute to the issue of animal health, public health and the lack of information on parasitology studies in the country, hence the importance of this research. ${ }^{5}$

\section{Materials and methods}

Place of study and animals: The study was carried out in four (4) farms, located in Colombia, in the city of Valledupar located between $10^{\circ} 29^{\prime}$ North latitude and $73^{\circ} 15^{\prime}$ 'West longitude, at a height of $168 \mathrm{~m}$., with an average annual temperature of $28.4^{\circ} \mathrm{C}$, which places it in a tropical forest climate formation. ${ }^{6}$ For the realization of the present investigation, 111 creole and mestizo sheep were used, on which a 
physical examination and diagnosis of the types and parasite load were carried out, each sheep being an experimental unit and the period of this study was carried out between May and August of the year 2019.

Sampling: The sheep was held by a hind limb, neck or body, avoiding its passage, cornering it is a good practice. Afterwards, the animal was mounted with both hands holding it by the neck, this is how said containment allowed a physical evaluation and sampling without problem. ${ }^{7}$ In this way, the physical examination stage could be carried out, carrying out a body evaluation, Famacha, identification of ectoparasites and the presence of lesions and submandibular edema. The collection was done with sterile gloves by stimulating the anal sphincter, approximately $15 \mathrm{~g}$ to $30 \mathrm{~g}$ of fecal matter were taken, which was later placed in collectors of fecal samples and the collector was properly closed, labeling with the identification number that will designate each animal. ${ }^{8}$

Stool analysis: The modified McMaster method was used. Likewise, a stool culture and Baermaan technique were performed with fecal samples that presented high parasitic loads, ${ }^{5}$ and their subsequent identification by measuring larval characteristics through digital capture and processing of images found in atlas of parasitology. The parasite load and the mean number of parasites identified in infected sheep per grams of feces were determined.

Statistical analysis: To determine the relationship between parasite load, Famacha, and body condition, a regression and linear correlation analysis was applied using the $\mathrm{R}$ statistical software and the Chisquare test as hypothesis test. ${ }^{9}$

\section{Results}

The presence of gastrointestinal endoparasites was determined microscopically in stool samples taken from sheep in the fattening stage in 4 farms, the results of which can be seen in Graph 1. $84.6 \%$ (94/111) of the total samples collected were positive for gastrointestinal endoparasites. The results obtained were expressed as positive and negative animals for the different parasites observed to determine the incidence.

The Mcmaster technique was used to quantify the eggs of gastrointestinal endoparasites present in the fecal samples taken from the sheep, the results of which are observed in Graph 2.

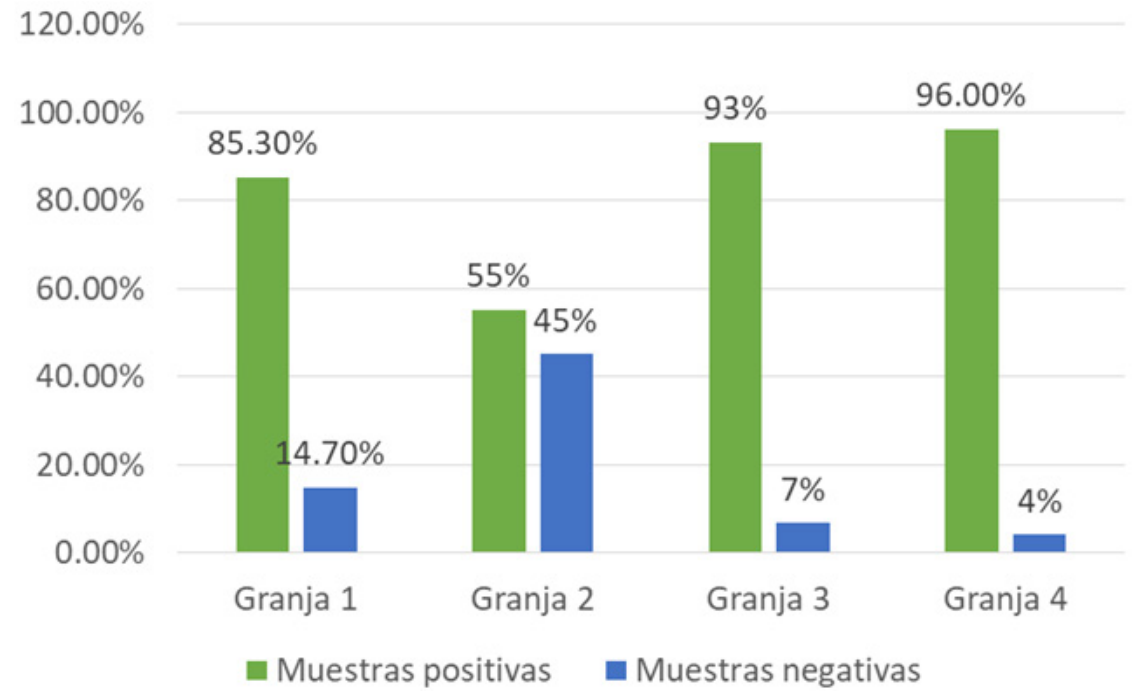

Graph I Distribution by farm of positive and negative sheep for gastrointestinal endoparasites.

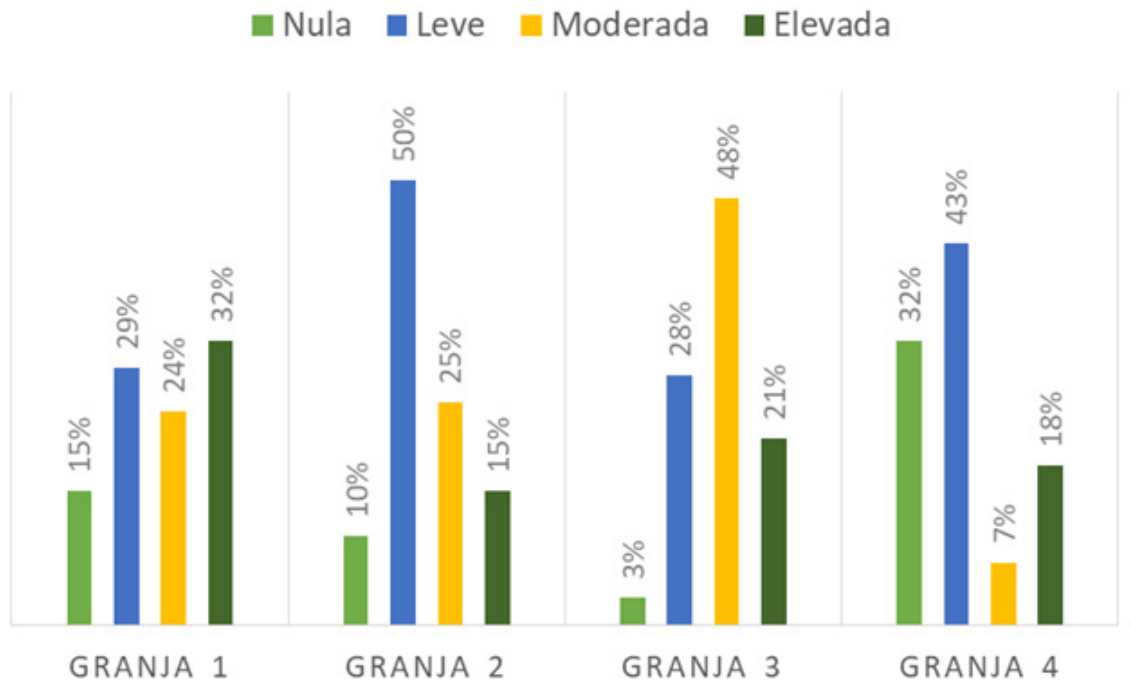

Graph 2 Distribution by farm of the parasitic loads of sheep. 
Of the 111 sheep sampled, only 94 of them (84.6\%) were parasitized, while, of this population, only 25 sheep, that is, $22.5 \%$ of this group had high parasite loads, where farm 1 was the one that presented more specimens with high parasite loads with a percentage of $9.9 \%$ (11/111), followed by Farm 3 with 5.4\% (6/111), then Farm 4 with a percentage of $4.5 \%(5 / 111)$ and finally, farm 2 , which had a lower number of specimens with high parasite loads, having a percentage of $2.7 \%(3 / 111)$.

The results obtained show a high percentage of light parasite load of eggs in the sheep sampled in the 4 farms. It should be noted that sheep with high parasite loads had a higher prevalence of the gastrointestinal endoparasite Haemonchus sp with a percentage of $9.9 \%(11 / 25)$, followed by this Cooperia with 6.3\% (7/25), Ostertagia sp $2.7 \%$ (3/25), Trichuris sp 0.9\% (1/25) Strongyloides sp 0.9\% (1/25), Eimeria $0.9 \%(1 / 25)$ and finally Trichostrongylus with a percentage $0.9 \%(1 / 25)$ for a total of $22.5 \%$.

On the other hand, no lice, ticks or sucking flies were found, that is, ectoparasites, in the animals sampled in the different farms and their absence may be due to the controls that the producers carry out, such as checking the flocks, use of good wires for the realization of the fences and also their maintenance and even the use of antiparasitics as a preventive measure to avoid infestations. On the other hand, it is estimated that $35 \%$ of the animals sampled were in an intermediate anemic state, followed by the acceptable anemic state with $28 \%$, optimal anemic state with $17 \%$, dangerous anemic state with $14 \%$ and finally the $6 \%$ of the sampled population had a fatal anemic state.

Of course, the body conditions of the sheep were evaluated, which is measured in the same way on a scale of 1 to 4 , where 1 is an animal with an obese body condition while 4 is an animal with an extremely thin body condition, being the Farm with the highest number of specimens with body conditions in 4 was farm 4 with $18 \%(5 / 28)$ while farm 2 did not obtain specimens with body conditions in 4 , that is, with $0 \%$.

This is how it was evaluated if there is a relationship between the body condition of the sheep with their anemic state through the use of the Software $\mathrm{R}$, which resulted in $\mathrm{p}>0.05$, therefore it is estimated that there is no relationship between the two variables studied. The results can be seen in Table 1 and Table 2 .

Table I Relationship between body condition and anemic status of the sampled sheep

\begin{tabular}{|c|c|c|c|c|c|c|c|}
\hline & & \multicolumn{5}{|c|}{ Famacha } & \multirow{2}{*}{ Total } \\
\hline & & Opt. & Acept. & Interm. & Pelig. & Fatal & \\
\hline & Count & 2 & 6 & 4 & 3 & 2 & 17 \\
\hline & I & & & & & & \\
\hline & $\%$ & $10,5 \%$ & $19,4 \%$ & $10,3 \%$ & $18,8 \%$ & $33,3 \%$ & $15,3 \%$ \\
\hline & Count & 8 & 15 & 11 & 6 & I & 41 \\
\hline & 2 & & & & & & \\
\hline & $\%$ & $42,1 \%$ & $48,4 \%$ & $28,2 \%$ & $37,5 \%$ & $16,7 \%$ & $36,9 \%$ \\
\hline \multicolumn{8}{|l|}{ CC } \\
\hline & Count & 7 & 9 & 18 & 5 & 3 & 42 \\
\hline \multicolumn{8}{|c|}{3} \\
\hline & $\%$ & $36,8 \%$ & $29,0 \%$ & $46,2 \%$ & $31,3 \%$ & $50,0 \%$ & $37,8 \%$ \\
\hline & Count & 2 & 1 & 6 & 2 & 0 & 11 \\
\hline \multicolumn{8}{|c|}{4} \\
\hline & $\%$ & $10,5 \%$ & $3,2 \%$ & $15,4 \%$ & $12,5 \%$ & $0,0 \%$ & $9,9 \%$ \\
\hline \multirow{3}{*}{ Total } & Count & 19 & 31 & 39 & 16 & 6 & 111 \\
\hline & & & & & & & \\
\hline & $\%$ & $100,0 \%$ & $100,0 \%$ & $100,0 \%$ & $100,0 \%$ & $100,0 \%$ & $100,0 \%$ \\
\hline
\end{tabular}

Table 2 Chi-Pearson's square between anemic state and body condition

\begin{tabular}{llll}
\hline Chi-square tests & & & \\
\hline & Value & df & $\begin{array}{l}\text { Asymptotic } \\
\text { meaning (bilateral) }\end{array}$ \\
\hline Pearson's Chi-square & $10,432^{\mathrm{a}}$ & 12 &, 578 \\
Likelihood ratio & $\mathrm{I}, 252$ & 12 &, 507 \\
N of valid cases & $\mathrm{II}$ & &
\end{tabular}

all cells (55.0\%) have expected a count less than 5 . The minimum expected count is .59
Likewise, the relationships that exist between the body condition and the parasite load presented by the 111 specimens sampled distributed in the different farms where, according to the results raised in the Chi-square test, there is a relationship because $\mathrm{p}<0.05$ as shown manages to show in Table 3 and Table 4.

Finally, the relationship that exists between the anemic state of the sheep was made, which was determined using the Famacha technique and the parasite load presented by the sheep, which resulted in the fact that there is a relationship between both variables because $p<0.05$ (Table 5 and 6). Due to the reduced number of infective larvae obtained in stool cultures, it was not possible to establish a percentage of species composition sufficiently representative of the sample, hence only the presence of species can be reported. 
Table 3 Relationship between body condition and parasite load presented by the sampled specimens

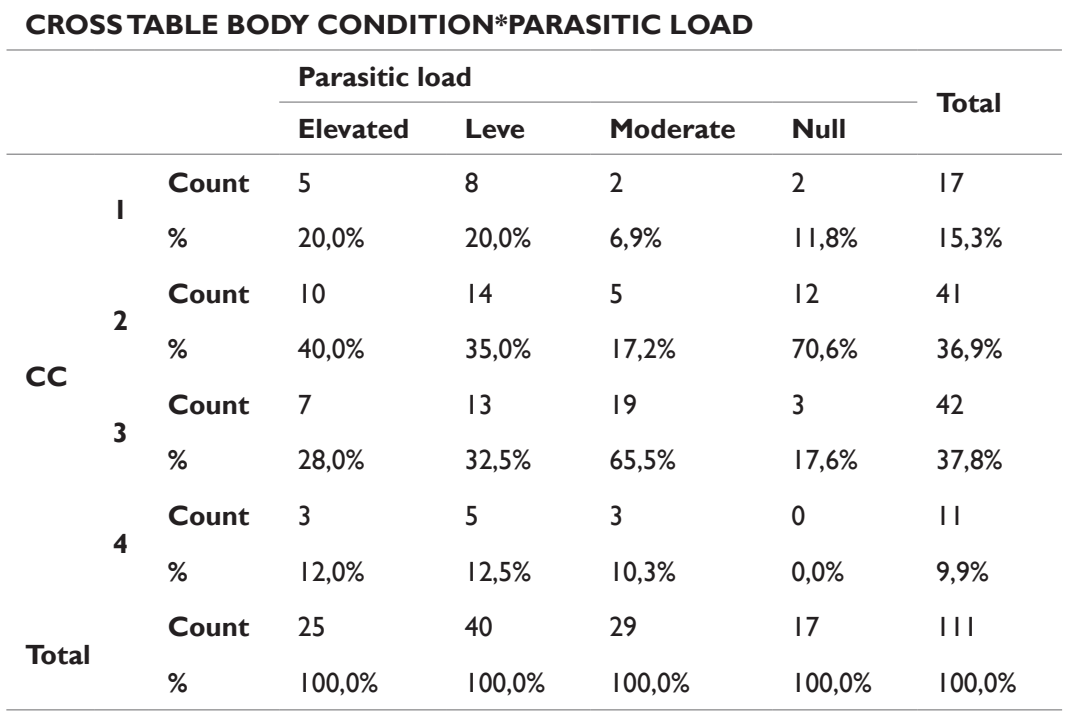

Table 4 Pearson's Chi-Square taking into account the body condition and the parasite load presented by the sampled sheep

\begin{tabular}{llll}
\hline \multicolumn{1}{c}{ Chi-square tests } & & & \\
\hline & Value & df & Asymptotic meaning (bilateral) \\
\hline Pearson's Chi-square & $21,490^{\mathrm{a}}$ & 9 &, $01 \mathrm{I}$ \\
Likelihood ratio & 22,547 & 9 &, 007 \\
$\mathrm{~N}$ of valid cases & $\mathrm{III}$ & &
\end{tabular}

Table 5 Relationship between body condition and anemic status of the sampled sheep

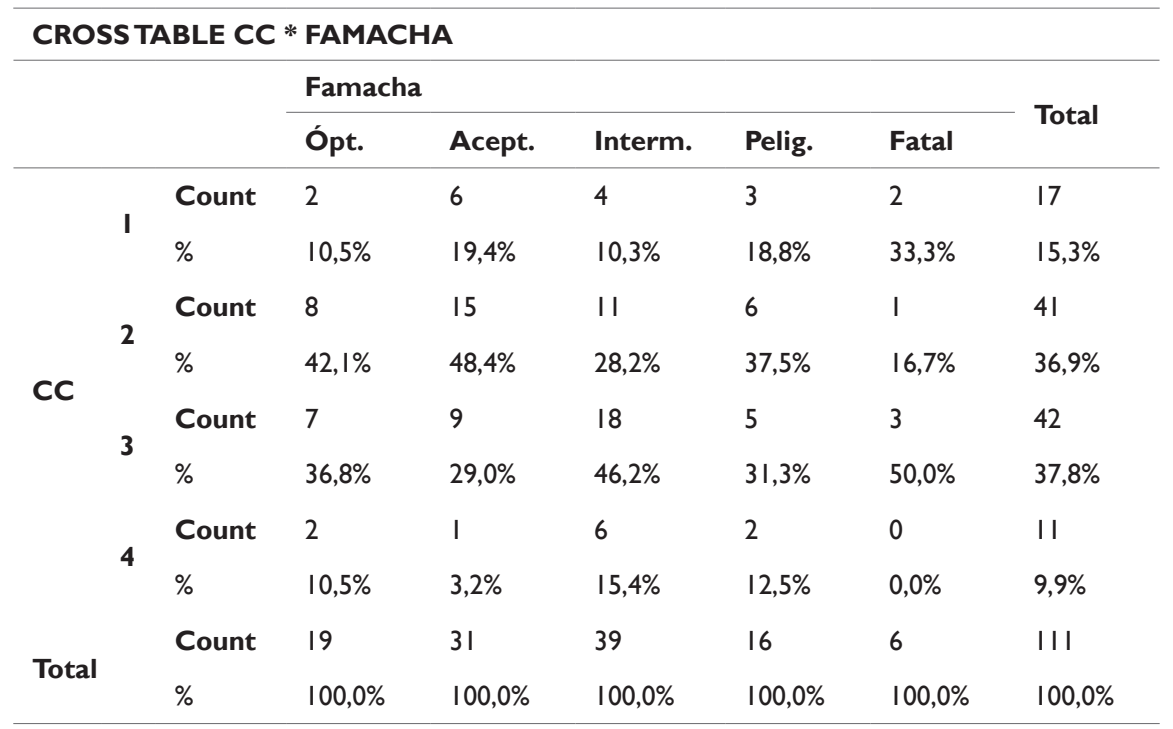

Table 6 Chi-Pearson's square between anemic state and body condition

\begin{tabular}{llll}
\hline \multicolumn{1}{l}{ Chi-square tests } & & \\
\hline & Value & df & Asymptotic meaning (bilateral) \\
\hline Pearson's Chi-square & $10,432^{\mathrm{a}}$ & 12 &, 578 \\
Likelihood ratio & $1 \mathrm{I}, 252$ & 12 &, 507 \\
N of valid cases & $\mathrm{I} 1 \mathrm{I}$ & &
\end{tabular}

a I cells (55.0\%) have expected a count less than 5 . The minimum expected count is .59

Citation: Silvestre CGA, Patricia HD, Karina BDA, et al.Association of ectoparasites and gastrointestinal endoparasites and body condition in sheep from four farms of the municipality of Valledupar, Cesar.J Microbiol Exp. 202I;9(3):6I-66. DOI: I0.15406/jmen.202I.09.00325 


\section{Discussion}

The current study indicated that the prevalence found is high, this may be due to the climatic conditions of the city of Valledupar since it provides the parasites with all the requirements that promote their life cycle, giving rise to a parasitic overpopulation, however, it is lower with respect to previous studies carried out in other departments such as Tolima with $98.5 \%$ where the presence of rains in some areas and crops was a key factor to predispose to a high degree the prevalence of parasites. ${ }^{10}$

Now, the parasitic loads had a high significance of low levels of parasitosis, however this does not necessarily mean that there is a minimum number of nematodes in the animal, since factors such as sensitivity of the MacMaster technique and time of year must be considered, since the sheep were evaluated during the dry season; that is to say, between May and August, a period that corresponds to the presence of hostile conditions for nematodes, and their presence may not be detected due to survival mechanisms such as hypobiosis. ${ }^{11}$ Even more, in tropical regions in the summer, low humidity reduces the levels of infestation in the pastures and the lambs born during the dry season remain free of infection until the onset of the rains, forming a totally susceptible group that acquires high parasitic loads and at the end of the rainy season, they decrease due to the acquisition of resistance (immunity) and hypobiosis of the larvae. ${ }^{10}$

Certainly the results obtained in this study indicate a higher prevalence of Haemonchus $s p$, with the species Haemonchus contortus being the most prevalent parasite ${ }^{11,12}$ and this may be due to the fact that females have a high capacity to oviposit per day, giving rise to approximately 5000 eggs per day, which are excreted through the feces of sheep, later hatch giving rise to a larva in stage L3 which is the infecting larva and ruminants will ingest this larva through the pasture. ${ }^{13}$ Now, the FAMACHA technique is a strategy that works only when the specimens are infested by Haemonchus $s p$ due to its hematophagous capacity par excellence, causing severe anemia in the animals, which is reflected in their ocular mucosa. ${ }^{5}$ For this reason, various studies using this technique to detect anemic animals and to be able to identify sheep resistant to gastrointestinal parasites, being able to minimize the appearance of resistance to antiparasitics. ${ }^{14,15}$

In this order of ideas, it can be affirmed that there is a relationship between the parasite load and FAMACHA, because the results obtained agree with other studies where animals with optimal Famacha results between 1 and 2 presen ${ }^{10,16,17}$ however, there were no significant differences $(p>0.05)$ in Famacha or body condition with the parasite load; This statement is consistent with investigations in the departments of Antioquia and Boyacá, where no relationship was found between Famacha, body condition and parasite load. ${ }^{4}$

Regarding body condition, supported by other studies, there is a non-significant trend, a low correlation and a low index of the coefficient of variability $(\mathrm{r} 2=0.5747)$, indicating that the relationship between these parameters does not fit the proposed model, since, unlike body weight, the assessment of body condition is a relatively subjective parameter. However, body condition reflects the nutritional status of an animal, and it is important to consider that low body condition animals are more susceptible to gastrointestinal parasites. Therefore, there are many factors to consider to determine whether the body condition in sheep is influenced by gastrointestinal parasitism, since a low relationship between these parameters was found. ${ }^{9}$

\section{Conclusions}

There is a high prevalence of gastrointestinal parasites in farms in the municipality of Valledupar, Cesar with $89 \%$, presenting significance in the prevalence of the parasite Haemonchus $s p$, taking into account that the identification of parasites was carried out only in sheep that presented high parasite loads and, in addition, they presented Famacha levels between serious and fatal. The animals did not show characteristic symptoms of parasitic infections such as submandibular edema and external lesions. There is a relationship between the anemic state and the parasite load that the sheep present, taking into account that Famacha turned out to be a useful technique to determine in which anemic state the sheep are, graduating these results on a scale of 1 to 5. It should be noted that the Body condition is not associated with the parasitic load of sheep and is responsible for the fact that this technique is subjective and that therefore the decrease in body mass and weight of sheep may be due to various factors and not necessarily to the presence of endoparasites, gastrointestinal and ectoparasites, considering that the latter were absent in this research.

\section{Recommendations}

The presence of parasitism in sheep production systems is associated with physical, biotic and abiotic factors, but it is also very important to carry out complementary activities that include paddock rotations and also to carry out constant maintenance of the drinkers so that these are kept clean and in this way reduce the presence of parasites in the facilities. Before applying parasitic treatments based on laboratory diagnostic tests, it is important to perform routine inspection techniques such as observation of the ocular mucosa to determine possible anemia using the Famacha technique to reduce costs in sheep producers. It should be noted that even after testing the association between the Famacha technique and the presence of gastrointestinal endoparasites, it is recommended to carry out validation studies of the technique in order to confirm its feasibility when diagnosing animals as anemic.

\section{Acknowledgments}

None.

\section{Conflicts of interest}

Authors declare that there is no conflict of interest.

\section{References}

1. Salazar CO. Evaluation of the implementation of Good Livestock Practices in the production of sheep and goats in the metropolitan area of the municipalities of Bucaramanga and Lebrija. [Master's degree work]. University of Manizales Faculty of Accounting, Economic and Administrative Sciences; Manizales, Colombia; 2015.

2. Bravo Luna GA. Rural entrepreneurship as an agricultural alternative in sheep culture for La Dorada Caldas in the village of Doña Juana. University of La Salle, Bogotá; 2017.

3. Bernal H. Effects of different grazing intensities on plant production, productive performance and parasite load in hair sheep in the municipality of El guamo-Tolima. Agreement between the National University of Colombia, the Palmira-University of Tolima School of Agricultural Sciences, the School of Veterinary Medicine and Zootechnics; 2014.

4. Díaz A, Chavarro G, Pulido M, et al. Coproparasitological study in grazing sheep in Boyacá, Colombia Coproparasitological study in grazing sheep in Boyacá, Colombia. Journal of Animal Health. 2017;39(1):1-8.

5. Rodriguez J, Arece J, Olivares J, et al. Helmpintics, resistance and the Famacha method. Cuban experience in sheep. Animal Health Magazine. 2015;37(1):57-63.

6. Valledupar Mayor's Office; 2016.

7. Mendoza A, Verumen A, Santamaría E, et al. Sheep clinical diagnosis. Autonomous Juárez University of Tabasco; 2011. 
8. Guamanquispe PJ. Diagnosis of Ectoparasites and Endoparasites prevalent in sheep from the Isinvilí parish, Cantón Sigchos. Pregado thesis; 2017.

9. Masson M, Gutiérrez G, Puicón V, et al. Helminthiasis and gastrointestinal eimeriosis in alpacas reared to pasture in two communal farms in the Pasco region, Peru, and their relationship with weight and body condition. Journal of Veterinary Research of Peru. 2016;27(4):805-812.

10. Laviano Medina HD. Prevalence of gastrointestinal parasites in sheep in the department of Tolima. Ibagué: University of Tolima; 2017.

11. Cepeda Martínez ER. Parasitological study of gastrointestinal nematodes in sheep from the municipality of Ubaté, Cundinamarca. Universidad Pedagógica y Tecnológica de Colombia; 2017.

12. Zapata R, Velásquez R, Herrera L, et al. Prevalence of Gastrointestinal Nematodes in sheep and goat production systems under confinement, semi-confinement and grazing in Municipalities of Antioquia, Colombia. Journal of Veterinary Research of Peru. 2016;27 (2):344-354.

13. Luck R, Avendaño L, Ail C, et al. Ovicidal and larvicidal activity of aqueous extracts of Pluchea ericea and Artemisia tridentata on Haemonchus contortus. Ecosystems and Agricultural Resources Magazine. 2018;5(3):149-156.
14. Appel V, Quiroz L, Noguera D. Application of the Famacha Method in two types of goat farms in Popayán (Cauca, Colombia). Veterinary Medical Journal. 2017;35:45-52.

15. Salgado S, Carrillo F, Escalera F, et al. Tests to identify sheep resistant to gastrointestinal parasites in San Pedro Lagunillas Nayarith. Veterinary Fan Magazine. 2017;7(3):63-71.

16. Ensuncho C, Castellanos A, Maza L, et al. Prevalence and Level of Gastrointestinal Nematode Infection in Sheep of Hair in Grazing in Four Municipalities of Cordoba, Colombia. Scientific Journal FCV-LUZ. 2014;24(5):414-420.

17. Rossanigo C, Page W. Evaluation of FAMACHA in the control of gastrointestinal nematodes in goats from San Luis (Argentina). ESTUARY. Journal of Agricultural Research. 2017;43(3):239-246. 